\section{Quiste epidermoide en región parotídea. Reporte de caso y revisión de la literatura}

\section{Epidermoid cyst in the parotid region. A case report and review of the literature}

\section{Resumen}

Los quistes epidermoides son lesiones quísticas benignas que se desarrollan de componentes epiteliales anormales de tejido ectodérmico formado durante el periodo fetal (congénito) o por epitelio implantado después de una cirugía o trauma (adquirido). El quiste epidermoide es considerado una lesión benigna que afecta la región del pericráneo, cara, cuello, espalda y torso, el 7\% de estos quistes ocurren en la región de la cabeza y el cuello y solo el 1,6\% representa la cavidad oral. A continuación, se presenta un caso clínico con diagnóstico histopatológico de quiste epidermoide en la región parotídea, el cual no presentó un compromiso del parénquima glandular, el cual fue tratado mediante escisión quirúrgica completa, sin alteración o daño al nervio facial, con seguimiento postoperatorio de tres años sin recidiva.

Palabras clave: Quiste epidermoide; Región parotídea; Diagnóstico (fuente: DeCS BIREME).

\begin{abstract}
Epidermoid cysts are benign cystic lesions that develop from abnormal epithelial components of ectodermal tissue formed during the fetal period (congenital) or from epithelium implanted after surgery or trauma (acquired). The epidermoid cyst is considered a benign lesion that usually affects the scalp, face, neck, back, and torso. $7 \%$ of these cysts occur in the head and neck, whereas the oral cavity represents only $1.6 \%$. A clinical case is presented with a histopathological diagnosis of an epidermoid cyst in the parotid region, which did not present compromise of the glandular parenchyma, that was treated with complete surgical excision, without alteration or damage to the facial nerve, with a three-year postoperative follow-up without recurrence.
\end{abstract}

Keywords: Epidermoid cyst; Parotid region; Diagnosis (source: MeSH NLM).

\section{Caso Clínico}

Kevin Andrew Gómez Hernández ${ }^{1, a}$, Roberto Morales Mercado ${ }^{1, b}$, Brizeida Mireya Olmedo Campos ${ }^{2, c}$, Patricia Tello Paniagua ${ }^{1, d}$

${ }^{1}$ Universidad Nacional Autónoma de México, Facultad de Odontología, División de Estudios de Posgrado e Investigación, (DEPel - UNAM), Ciudad de México, México.

${ }^{2}$ Universidad Autónoma Metropolitana, Unidad Xochimilco, División de Ciencias Biológicas y de la Salud, (UAM DCBS), Ciudad de México, México.

a Residente de tercer año, cirugía oral y maxilofacial.

${ }^{b}$ Especialista en cirugía maxilofacial.

c Especialista en patología y medicina bucal.

${ }^{d}$ Especialista en periodoncia e implantología.

\section{Correspondencia:}

Kevin Andrew Gómez Hernández: Andrew.gmz.ula@ gmail.com

Dirección: Saratoga 802, colonia Portales Norte, delegación Benito Juárez, Código Postal: 03300. Ciudad de México.

ORCID: 0000-0002-8987-9765

\section{Coautores:}

Roberto Morales Mercado: maxilo.morales19@hotmail.com ORCID: 0000-0001-5576-6052

Brizeida Mireya Olmedo Campos: mireya_1507@hotmail.com ORCID: 0000-0002-3174-2176

Patricia Tello Paniagua: tp_patty@yahoo.com.mx ORCID: 0000-0001-9710-1075

\section{Editor:}

Donald Ramos-Perfecto

Universidad Nacional Mayor de San Marcos, Perú.

Conflicto de intereses: los autores declaran no tener conflictos de interés.

Fuente de financiamiento: autofinanciado.

Recibido: 12/02/21

Aceptado: $22 / 03 / 21$

Publicado: 01/07/21

(c) Los autores. Este artículo es publicado por la revista Odontología Sanmarquina de la Facultad de Odontología, Universidad Nacional Mayor de San Marcos. Este es un artículo de acceso abierto, distribuido bajo los términos de la licencia Creative Commons Atribución 4.0 Internacional (CC BY 4.0) [https://creativecommons.org/ licenses/by/4.0/deed.es] que permite el uso, distribución y reproducción en cualquier medio, siempre que la obra original sea debidamente citada de su fuente original. 


\section{Introducción}

Los quistes cutáneos son lesiones frecuentes de la piel, siendo los quistes epidermoides los de mayor incidencia, estos se originan del infundíbulo del folículo piloso debido a un crecimiento epitelial por una inflamación crónica del folículo. Estas lesiones son consideradas como malformaciones que ocurren en el área de cabeza y cuello con una frecuencia de $1,6 \%$ a $6,9 \%$. Estos se clasifican dependiendo de sus características histológicas en epidermoide, dermoide o teratoide ${ }^{1}$. El quiste epidermoide fue descrito por primera vez en 1807 por Pinzón ${ }^{2}$ y también es conocido como: quiste de tipo infundibular folicular, quiste de queratina, quiste de inclusión epidérmica o quiste epitelial ${ }^{3}$.

El quiste epidermoide se divide en congénito y adquirido. El primero se desarrolla a partir de la inclusión congénita de tejido ectodérmico durante el desarrollo embriológico y el tipo adquirido se origina a través de la implantación del epitelio en tejidos mesenquimales más profundos ${ }^{4}$. Clínicamente se presenta como un nódulo en la dermis o capa subcutánea, es de crecimiento lento e indoloro y puede alcanzar un gran tamaño, así como causar dolor cuando este llega a presentar una ruptura de su pared, aumentando así el riesgo de complicaciones. La escisión quirúrgica completa es el tratamiento de elección, a pesar de su bajo riesgo de transformación maligna siempre debe realizarse el estudio histopatológico de la totalidad del espécimen ${ }^{2,5}$.

Epidemiología. Los quistes dermoides y epidermoides son quistes benignos del desarrollo, son de crecimiento lento que surgen del tejido ectodérmico y pueden presentarse en cualquier parte del cuerpo, como el pezón, los genitales y el área palmoplantar. La cara, el cuello, el área periauricular y la parte superior del tronco son los más afectados ${ }^{6}$ y solo representan menos del $7 \%$ de los quistes que afectan la región de la cabeza y el cuello ${ }^{7}$.

Los quistes epidermoides pueden desarrollarse en cualquier parte del cuerpo y generalmente se diagnostican alrededor de la tercera década de vida ${ }^{6,8}$.

Etiología. New y Erich en 1937 clasificaron a los quistes cutáneos con base en su etiología:

- Quistes cutáneos congénitos del tipo teratoma: Se desarrollan de las capas embrionarias germinales, dependiendo de la capa predominante pueden contener piel, cabello, dientes, etc.

- Quistes cutáneos adquiridos: Denominados también como quistes de inclusión, son el resultante de piel implantada traumáticamente en tejidos más profundos.

- Quistes cutáneos congénitos o de inclusión: Son el resultante de la inclusión de células dérmicas, desplazadas a lo largo de las líneas de fusión embrionaria y se pueden subdividir en cuatro grupos ${ }^{9}$.

- Quistes alrededor de los ojos y órbitas: originadas de la fisura naso-óptica.
- Quistes nasales: resultantes de la intrusión en la fisura frontonasal.

- Quistes de piso de boca, submental y submaxilar: originados del primer y segundo arco faríngeo.

- Quistes supraesternales: suboccipitales, tiroideos, labio inferior y paladar ${ }^{10}$.

Los quistes epidermoides son una protuberancia llena de líquido que se originan en el infundíbulo folicular y se encuentran justo debajo de la superficie de la piel. Las lesiones suelen aparecer de forma espontánea, sin embargo, también se les han considerado quistes de inclusión epidérmica, debido a que una lesión, trauma o a incisiones cutáneas, las células epidérmicas penetran profundamente en la piel y se multiplican ${ }^{6}$.

Los quistes epidermoides de presentación temprana y localización atípica pueden ser signos del síndrome autosómico dominante de Gardner, una enfermedad asociada a pólipos colorrectales con un alto grado de desarrollo hacia la malignidad. Múltiples quistes epidermoides en el tronco y las extremidades pueden ser sugerentes del síndrome nevoide de células basales o síndrome de Gorlin. En el síndrome de Favre-Racouchot (elastosis nodular con quistes y comedones), los quistes epidermoides pueden resultar de daño solar crónico en pacientes ancianos ${ }^{6,11}$.

Los medicamentos que actúan mediante la inhibición del gen BRAF como la ciclosporina vía oral y el imiquimod tópico, han sido ligados a la aparición de múltiples quistes epidermoides ${ }^{12}$.

Las complicaciones que se han reportado son raras, pero incluyen: infección, fístulas cutáneas, ruptura de la pared del quiste ocasionando una reacción de cuerpo extraño, reacción de células gigantes mediada por queratina ${ }^{13}$. La infección secundaria en etapas más avanzadas puede ocasionar: osteomielitis, meningitis, abscesos cerebrales; e incluso se ha reportado erosión ósea, extensión intracraneal y desplazamiento de estructuras importantes ${ }^{14}$.

Se han reportado tasas del 1\% de transformación maligna en los quistes epidermoides, en las que pueda desarrollarse carcinoma epidermoide quístico, carcinoma de células basales y melanoma in situ ${ }^{15,16}$.

Características clínicas. Los quistes epidermoides son de crecimiento lento y, por lo general, solo se encuentran después de alcanzar un cierto tamaño. Durante el examen físico, los quistes epidermoides se presentan como una masa movible e indolora en la dermis o capa subcutánea, con un orificio lleno de queratina en la superficie que lo expone al medio externo ${ }^{5,17}$.

Se presentan como nódulos dérmicos o subcutáneos de consistencia firme y de un diámetro que varía entre los $2 \mathrm{~mm}$ a los $50 \mathrm{~mm}$ y son desplazables sobre el tejido circundante $^{2}$.

Diagnóstico. El diagnóstico varía dependiendo del lugar en el cual se encuentre el quiste epidermoide, sin embargo, son necesarios los estudios de imagen antes del tratamiento quirúrgico para determinar la extensión. 
Una característica común de los quistes epidermoides por inclusión es que estos pueden estar comunicados a la superficie externa mediante una apertura puntiforme en la piel ${ }^{3,6}$.

Imagenología. El ultrasonido se ha convertido en una herramienta diagnóstica primaria para los aumentos de volumen en la región cervicofacial, sin embargo, los quistes epidermoides tienen una apariencia no específica y requieren de más imágenes para orientar un correcto diagnóstico, sin embargo, se ha reportado una sensibilidad del $80 \%$ y una especificidad del $95,4 \%{ }^{18}$.

Se observan como una estructura ovoide o esférica en un $71 \%$, lobulada en un $21 \%$ y tubular en un $8 \%$, localizada en la dermis o en el tejido celular subcutáneo. Los quistes epidermoides en la región de la cabeza y el cuello son en su mayoría hiperecoicos con poco o nulo refuerzo sonoro posterior. En ocasiones presentan una ecogenicidad interna por los restos epiteliales presentes en el quiste, o también como una apariencia pseudoquística (zonas hiperecoicas internas y áreas hipoecoicas filiformes) resultante de los depósitos de queratina o colesterol; y presentan una imagen característica de piel de cebolla ${ }^{19}$.

En quistes epidermoides con ruptura se puede observar una zona circundante hipoecoica con colección de líquido, debido a la inflamación que causa en el tejido adyacente ${ }^{6}$.

Las imágenes a color tipo Doppler se muestran ausentes en el $83,3 \%$ y sólo el $16,7 \%$ muestra una vascularidad periférica en los quistes epidermoides que han tenido una ruptura de la pared ${ }^{19}$.

Tomografía computarizada. La tomografía computarizada juega un papel muy importante en el diagnóstico y es fundamental para determinar los bordes de la lesión y el manejo quirúrgico.

En las imágenes tomografías, el quiste epidermoide se observa como una estructura bien encapsulada, de una densidad heterogénea por la mezcla de queratina y de grasa, presentando en ocasiones calcificaciones en su interior y la pared puede reforzarse con el uso de medios de contraste.

Se han identificado tres patrones importantes para los quistes epidermoides asociados al hueso: esclerosis, erosión y la formación de una fosa con atenuación del hueso ${ }^{6}$.

En general los quistes epidermoides tienen una forma ovoide con un borde no infiltrado, los márgenes superficiales del quiste regularmente tocan la parte profunda de la piel, el contenido del quiste es mucoso y con calcificaciones ${ }^{6}$.

Resonancia magnética. Los hallazgos en la resonancia magnética dependen de la maduración del quiste, su densidad y la cantidad de queratina que contiene ${ }^{6}$.

En un quiste con cápsula rota se observa una pared septada, gruesa e irregular acompañada de un reforzamiento borroso indistinta en los tejidos adyacentes.

En resumen, las características en la resonancia magnética incluyen una masa confinada al tejido celular subcutáneo con una señal T2 alta, con la posibilidad de presentar una intensidad baja dependiendo del contenido del quiste, así como una pared que realza al medio de contraste en T1. El valor más importante de la resonancia magnética es demostrar si la lesión presenta invasión al tejido adyacente ${ }^{6}$.

Biopsia por aspiración con aguja delgada. En la evaluación citológica se pueden observar células escamosas de característica benigna, células epiteliales escamosas anucleadas y restos de células amorfas ${ }^{20}$, sin embargo, algunos autores mencionan que no se debe realizar la punción del quiste debido al incremento del riego de infección ${ }^{14}$.

La biopsia por aspiración con aguja delgada puede confundir el diagnóstico debido a que algunos carcinomas de células escamosas y lesiones malignas que presentan metaplasia escamosa y pueden compartir características de benignidad con los quistes dermoides ${ }^{9}$.

Clasificación. Los quistes cutáneos pueden clasificarse en tres tipos principales basado en su morfología y en su patrón de diferenciación

- Epitelio escamoso estratificado

- Epitelio escamoso no estratificado

- Ausencia de epitelio

Los quistes epidermoides se encuentran dentro de la primera clasificación ${ }^{6}$.

En 1937 New y Erich clasificaron los quistes dermoides con base en su etiología:

- Implantación adquirida.

- Congénito.

- Inclusión congénita ${ }^{10}$.

Meyer en 1955 clasifica a los quistes dermoides como:

- Epidermoides: se encuentran recubiertos de una capa de epitelio simple escamoso rodeada de tejido conectivo sin algún anexo cutáneo.

- Verdaderos dermoides: es una cavidad epitelial con apéndices cutáneos como folículos pilosos, glándulas sebáceas y sudoríparas. La cavidad está llena con células de descamación, queratina y cabello.

- Quistes teratoides: es también una cavidad de recubrimiento epitelial que contiene apéndices cutáneos y tejido conectivo derivado de musculo, hueso, dientes y membranas mucosas, sin embargo, estas se encuentran confinadas a ovarios y testículos ${ }^{21,22}$.

Diagnóstico diferencial. El diagnóstico diferencial en la región parotídea incluye: quiste de retención mucosa, bloqueo unilateral del conducto parotídeo, infección de la glándula parótida. Otras opciones de tumores mesenquimales benignos incluyen: lipoma, fibroma, hemangioma, neurofibroma. Se incluyen también tumores benignos de la glándula parótida como el adenoma 
pleomorfo, y tumores malignos de la parótida, e incluso enfermedad de Hodking, y linfoma no Hodking ${ }^{23}$.

Histopatología. Las características macroscópicas del quiste epidermoide se observan como una bolsa quística llena de material con apariencia de queso. El estudio histopatológico muestra una cavidad que esta revestida de epitelio escamoso estratificado que representan a la dermis. Se distingue una capa bien desarrollada de células granulares y el lumen contiene ortoqueratina en degeneración. En ocasiones, cuando la capa epitelial está rota, se observa una reacción inflamatoria granulomatosa, incluyendo células gigantes multinucleadas, en la pared del quiste debido a la queratina expuesta, ya que se presenta como una reacción de cuerpo extraño ${ }^{15}$.

En el 25\% de los casos puede observarse inflamación crónica y destrucción de la pared quística en quistes mayores a $1 \mathrm{~cm}^{3}$ de pacientes adultos jóvenes en un $50 \%{ }^{24}$.

Una lesión quística simple sin apéndices cutáneos se denomina quiste epidermoide. Mientras que los quistes dermoides son quistes con revestimiento epitelial que encierran apéndices de la piel como cabello, folículos pilosos, glándulas sebáceas o sudoríparas. En el quiste teratoide se pueden encontrar tejidos como músculos, cartílago y hueso en sus paredes ${ }^{6}$, sin embargo, existen otros tipos de quistes cutáneos que se pueden clasificar con base en el epitelio que estos presenten (Tabla) ${ }^{25}$.

Tratamiento. Los quistes cutáneos pequeños pueden ser monitorizados y no requieren de escisión quirúrgica completa de inmediato ${ }^{14}$, sin embargo, por lo general son retirados de forma quirúrgica cuando son detectados, o bien, posterior a un examen clínico y radiográfico riguroso. La disección meticulosa del periostio y el tejido adyacente debe ser completada sin la ruptura de la pared quística ${ }^{3,11}$.

Los quistes pequeños pueden ser removidos mediante $\mathrm{CO} 2$, o laser YAG-erbium. Las lesiones más grandes pueden retirarse mediante una incisión con bisturí de manera convencional o mediante el método de Zuber $e t$ al. ${ }^{26}$. Posterior a la escisión quirúrgica la pieza siempre debe someterse a estudio histopatológico.

Si se llega a romper la cápsula del quiste alrededor del tejido o si esta se encuentra cerca de zonas anatómicamente peligrosas será recomendable un abordaje quirúrgico más amplio para la identificación y protección de dichas estructuras ${ }^{6}$.

\section{Reporte del caso}

Se presentó al Hospital General de Tulancingo, Hidalgo, un paciente masculino de 38 ańos, originario y residente del Estado de México, Su motivo de consulta fue por inconformidad estética en la región facial derecha ${ }^{27,28}$. Posterior a la anamnesis y a la exploración física no se reportaron antecedentes heredofamiliares importantes, el paciente refirió tener hipertensión arterial sistémica bajo control y negó antecedentes traumáticos o quirúrgicos.

Clínicamente presentó un aumento de volumen asintomático en la región parotídea del lado derecho de 12 años de evolución, de crecimiento gradual hasta el tamańo actual (Figura 1). Se realizó una tomografía computarizada en la cual se mostró una zona hipodensa bien delimitada y de bordes regulares en la región parotídea del lado derecho, asociada a planos superficiales, que no involucra tejidos adyacentes (Figura 2).

Se programó para escisión en el quirófano mediante anestesia general. Se procedió a realizar un abordaje tipo Blair modificado mediante una incisión en la piel de la región preauricular y posterior al lóbulo de la oreja, así como una descarga hacia el borde anterior del músculo esternocleidomastoideo (Figura 3).

Se procedió a realizar una disección roma hasta exponer la cápsula quística, la cual se retiró sin ruptura de esta. Se corroboró la hemostasia y se suturó por planos. A la observación macroscópica del espécimen, éste era una masa globular de superficie lisa color grisáceo con áreas rugosas y blanquecinas, al corte presentó salida de material de aspecto caseoso de olor fétido (característico de queratina). Histológicamente se reporta una lesión quística con una pared de tejido fibroso laxo, revestida por epitelio escamoso estratificado delgado, libre de procesos interpapilares con capa granular prominente, así como abundante producción y descamación de láminas de ortoqueratina, sin presencia de anexos cutáneos. El diagnóstico es consistente con quiste epidermoide (Figura 4). Al seguimiento posterior hasta 3 años, el paciente no presentó daño al nervio facial o una fístula salival (Figura 5).

\section{Discusión}

Se han descrito dos teorías sobre la patogenia de los quistes epidermoides, una de ellas menciona la implantación

Tabla. Clasificación de quistes epidermoides con base en el epitelio que presentan

\begin{tabular}{llll}
\hline Epitelio escamoso estratificado & Epitelio escamoso no estratificado & Ausencia de epitelio (pseudoquiste) \\
\hline - Quiste epidermoide del infundíbulo & - Hidrocistoma & Mucocele \\
- Quiste miliar & Quiste triquilemal & Q Quiste broncogénico del conducto tirogloso & Quiste digital mucoso \\
- Esteatocistoma & Q Quiste de la hendidura branquial & Quiste sinovial metaplásico cutáneo \\
- Queratoquiste cutáneo & - & Quiste cutáneo ciliado \\
- Quiste folicular pigmentado & & & \\
- Quiste dermoide & & \\
- Quiste verrucoso & & \\
\hline
\end{tabular}




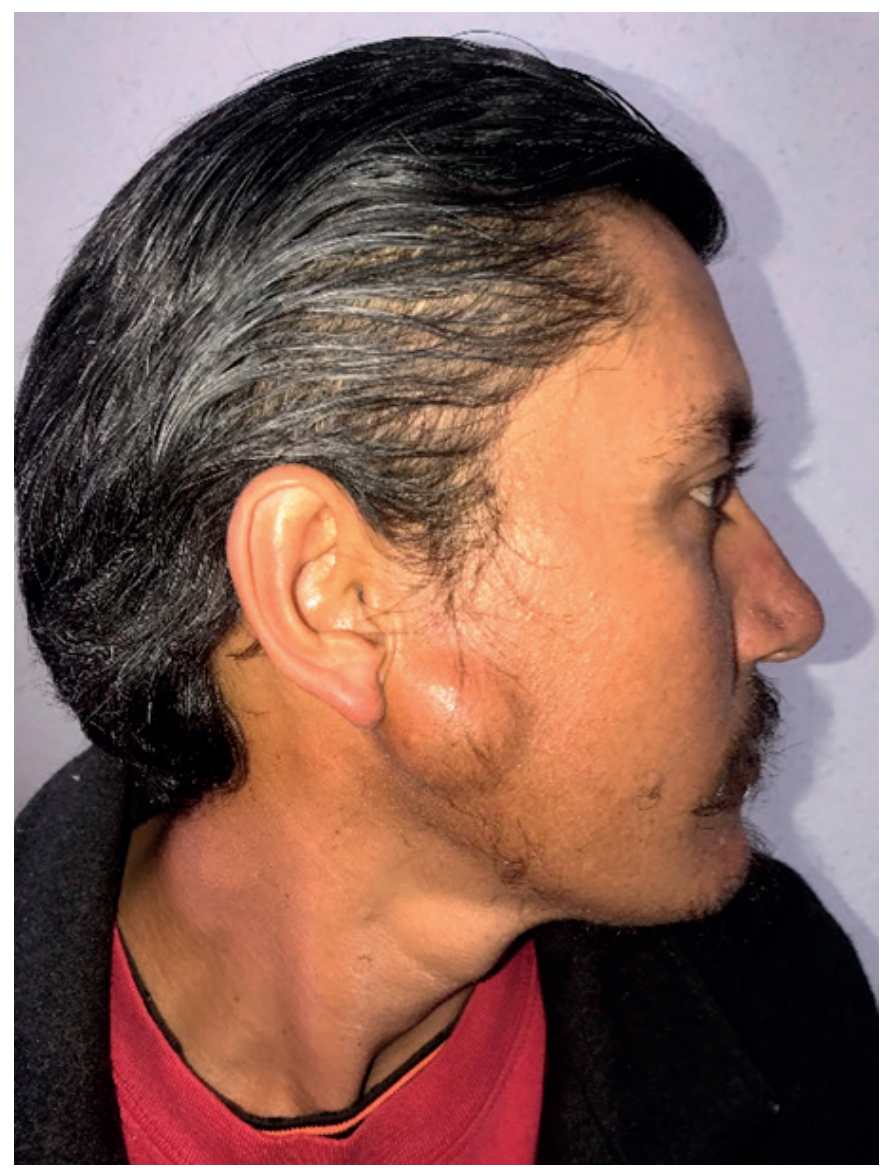

Figura 1. Aumento de volumen en la región parotídea derecha

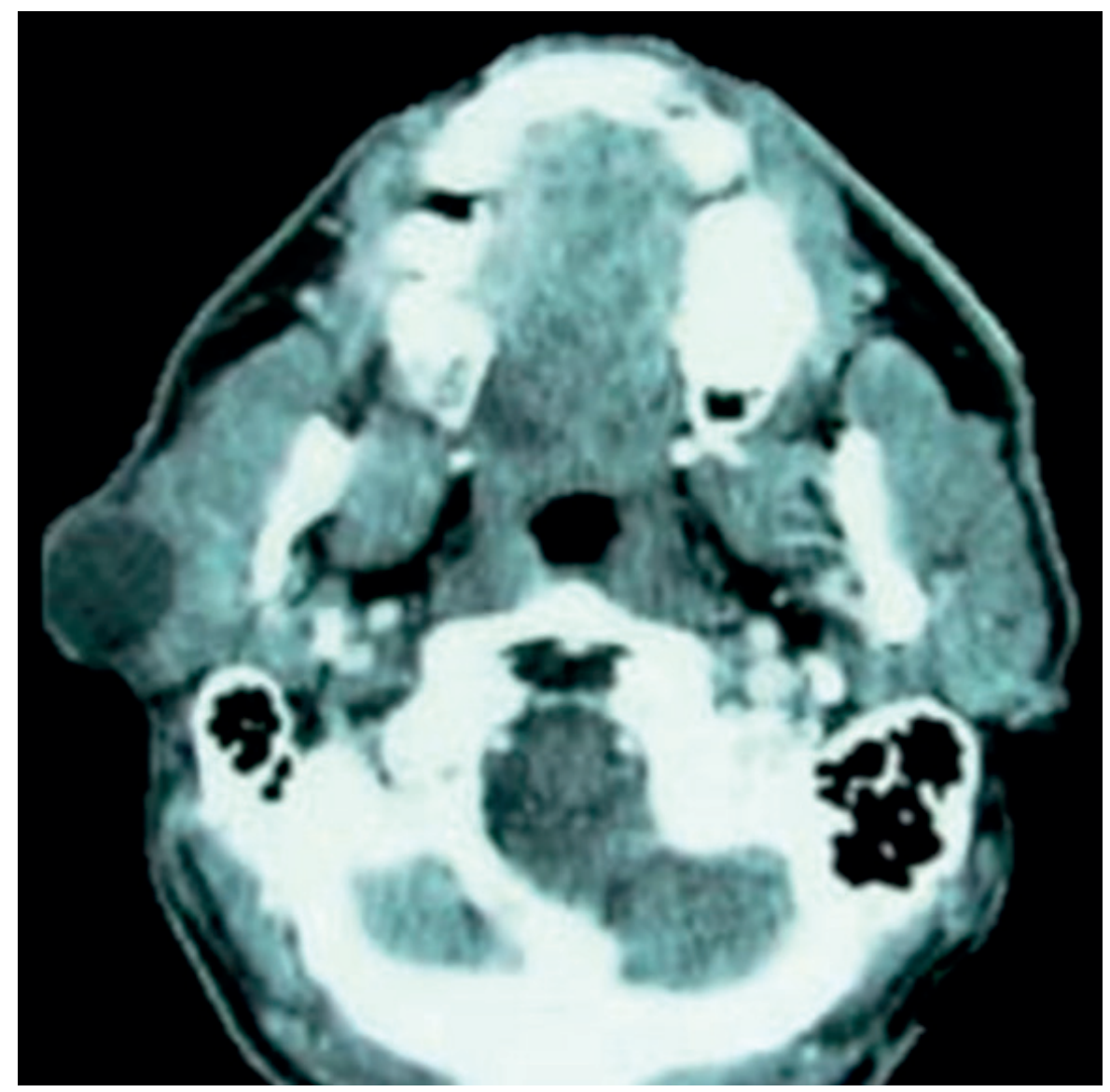

Figura 2. Tomografía computarizada evidenciando un área hipodensa de bordes bien definidos en la región parotídea del lado derecho 


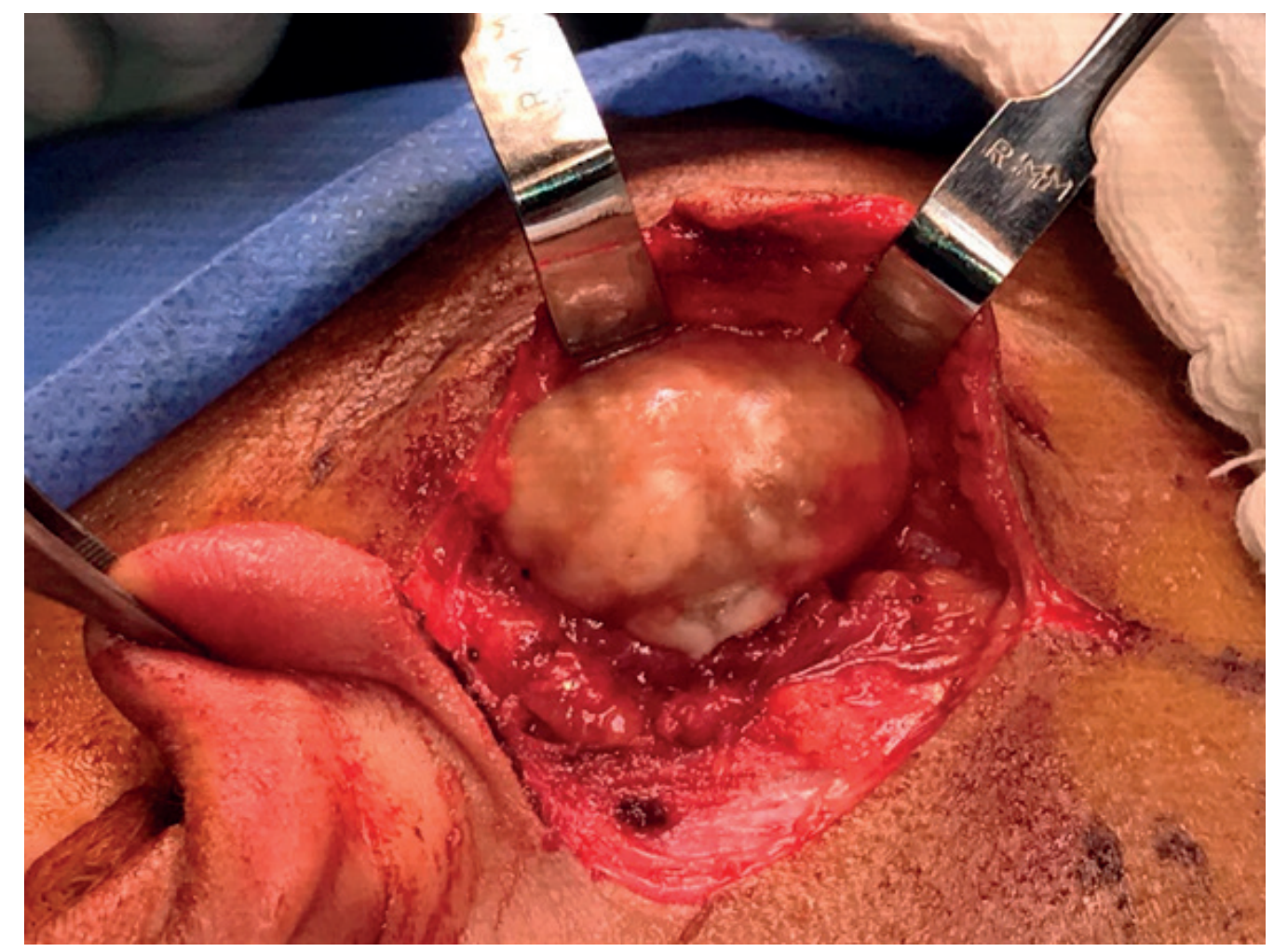

Figura 3. Exposición quirúrgica de la lesión sin ruptura de la cápsula

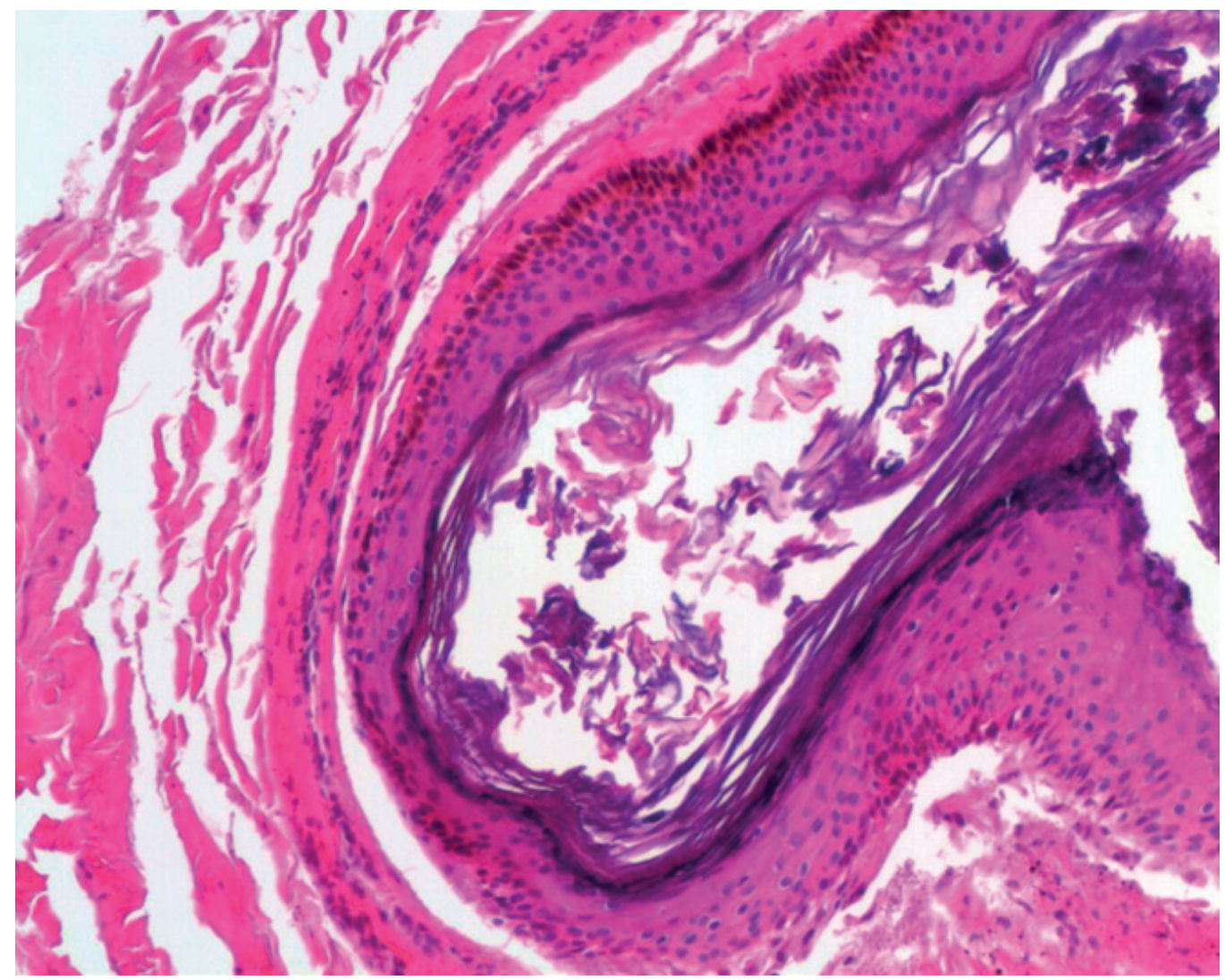

Figura 4. Microfotografía con tinción de hematoxilina y eosina a 40 aumentos en donde se observa una lesión quística cubierta de epitelio delgado escamoso con un lumen ocupado por abundantes láminas de ortoqueratina 


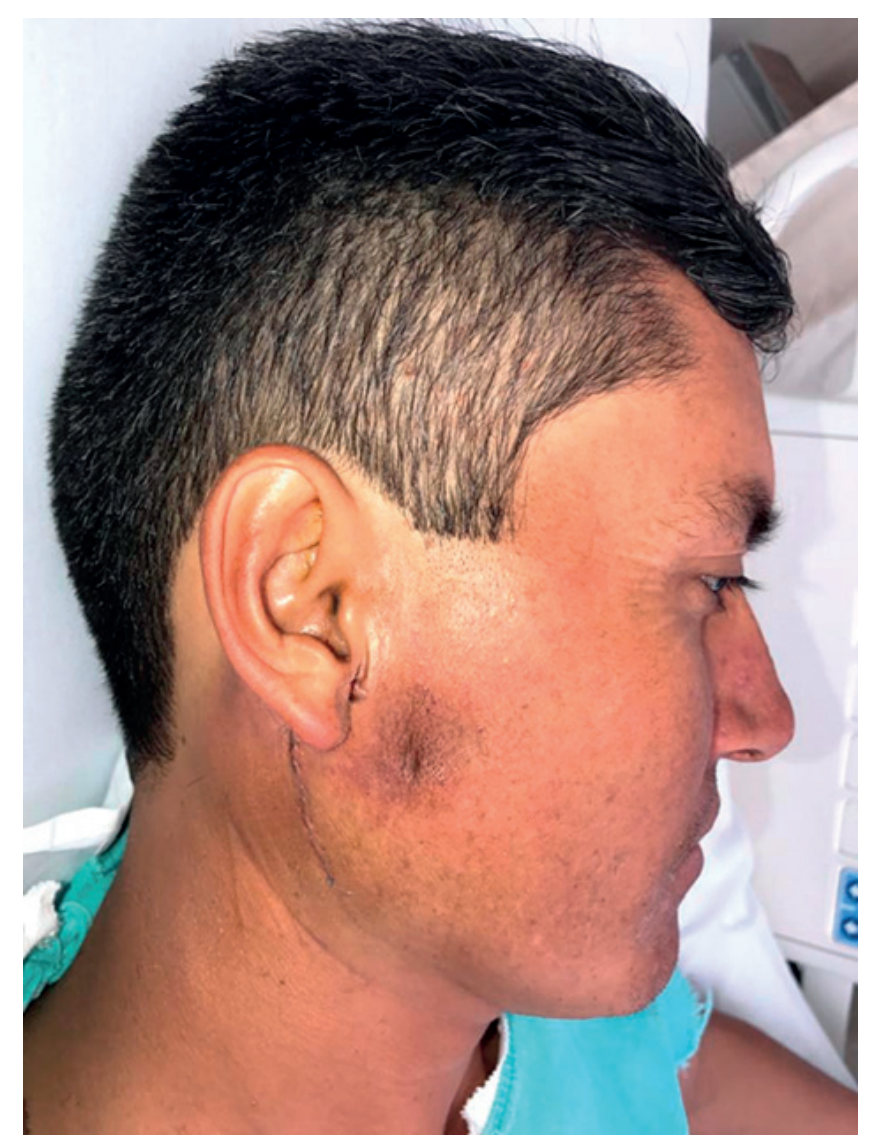

Figura 5. Fotografía postoperatoria con adecuada cicatrización sin evidencia de lesión al nervio facial

adquirida en la cual existe una inclusión traumática de células epiteliales en el tejido subyacente o por oclusión de alguna glándula sebácea. La segunda teoría aboga por la inclusión congénita del quiste, que resulta del atrapamiento del epitelio durante la fusión del primer y segundo arco faríngeo, durante la tercera y cuarta semana de gestación ${ }^{29}$.

Dutta et al. ${ }^{30}$ menciona en su estudio la distribución anatómica de 28 quistes epidermoides, reportando cinco en la región submandibular, uno en la región sublingual, cinco en el pabellón auricular, seis en la región periorbitaria, uno en una cicatriz previa de traqueostomía, seis en la región supraesternal, uno en la región del músculo esternocleidomastoideo y tres en la glabela ${ }^{30}$. Al-Katheeb et al. ${ }^{8}$ en su estudio retrospectivo menciona que, 488 pacientes con quistes cutáneos un $49 \%$ de quistes epidermoides, con un porcentaje de afección del $70 \%$. La presentación clínica de nuestro caso es rara debido a que el quiste epidermoide no se encontraba en una línea de fusión de los arcos faríngeos, el paciente negó algún antecedente de trauma o cirugía y no presentaba el signo patognomónico de una apertura puntiforme hacia el medio cutáneo en la superficie de la lesión ${ }^{3}$. Lo cual nos sugiere que el quiste epidermoide no surgió por trauma o de forma congénita. Incluso el paciente niega el antecedente de tratamiento bajo algún medicamento que actuara mediante la inhibición del gen BRAF como la ciclosporina o el imiquimod tópico ${ }^{12}$.
El quiste epidermoide del caso clínico actual se encontraba en planos anatómicos superficiales sin involucrar el parénquima de la glándula parótida, sin embargo, Ganesan et al. ${ }^{31}$ en el año 2015 describe un estudio llevado a cabo durante 25 años sobre quistes epidermoides en donde solo se reportó 1 en la glándula parótida y 3 en la glándula submandibular. Los quistes epidermoides representan el $5 \%$ de los tumores en la glándula parótida ${ }^{32}$ y $12,7 \%$ en el área preauricular ${ }^{3}$.

La edad de presentación concuerda con Gonzaga et al. 33; quien encontró que los quistes epidermoides tienen un rango entre 10 y 35 años de edad, el cual atribuye a un estímulo hormonal durante la pubertad, con lo cual explica la incidencia mayor en adultos jóvenes y en una relación hombres y mujeres de 2:1.

Existen pocos reportes sobre quistes epidermoides en la región parotídea y por lo general se atribuyen a inclusión epitelial, son de crecimiento lento e indoloro y presentan poca recidiva ante la resección quirúrgica 2,31,32.

Se puede concluir, según el caso clínico, que los quistes epidermoides en la región parotídea son de difícil diagnóstico debido a que pueden confundirse con patologías benignas que afectan el parénquima glandular, el abordaje clínico debe ser amplio para descartar lesiones de índole maligna e incluso para determinar la extensión de la lesión y lograr un tratamiento adecuado. El presente caso denota una presentación clínica rara en la región parotídea sin comprometer su parénquima. 


\section{Referencias bibliográficas}

1. Janarthanam J, Mahadevan S. Epidermoid cyst of submandibular region. J Oral Maxilofac Pathol. 2012;16(3):435-7.

2. Venegas RO, Martínez RB, Olivos BB, Vallejos MC, Zambra RM. Quiste epidermoide en la región preauricular: reporte de un caso. Rev otorrinolaringol cir cabeza cuello. 2011;71(2):167-70.

3. Kim CS, Na YC, Yun CS, Huh WH, Lim BR. Epidermoid cyst: A single-center review of 432 cases. Arch Craniofacial Surg. 2020;21(3):171-5.

4. Puranik SR, Puranik RS, Prakash S, Bimba M. Epidermoid cyst: Report of two cases. J Oral Maxilofac Pathol. 2016;20(3):546.

5. Ravindranath AP, Ramalingam K, Natesan A, Ramani P, Premkumar P, Thiruvengadam C. Epidermoid cysts: an exclusive palatal presentation and a case series. Int J Dermatol. 2009;48(4):412-5.

6. Hoang VT, Trinh CT, Nguyen CH, Chansomphou V, Chansomphou V, Tran TTT. Overview of epidermoid cyst. Eur J Radiol Open 2019;6:291-301. DOI: 10.1016/j.ejro.2019.08.003

7. Santos HB de P, Rolim LSA, Barros CC da S, Cavalcante IL, Freitas R de A, De Souza LB. Dermoid and epidermoid cysts of the oral cavity: A 48-year retrospective study with focus on clinical and morphological features and review of main topics. Med Oral Patol Oral y Cir Bucal. 2020;25(3):e359-63.

8. Al-Khateeb TH, Al-Masri NM, Al-Zoubi F. Cutaneous Cysts of the Head and Neck. J Oral Maxillofac Surg. 2009;67(1):52-7.

9. Dwivedi G, Gupta V, Patnaik U, Kumar M, Sood A, Upadhyay M. Dermoid Cyst of the Parotid Gland: A Rare Entity. Indian J Otolaryngol Head Neck Surg. 2019;71:809-12.

10. Phelan E, Colreavy M. Post-auricular dermoid cyst with intracranial extension-A rare finding. Int J Pediatr Otorhinolaryngol Extra. 2008;3(1):17-9.

11. Philbert RF, Sandhu NS. Nonodontogenic Cysts. Dent Clin North Am. 2020;64(1):63-85.

12. Mayer JE, Miller MD, Birlea SA. Symmetric multilocular epidermoid cysts on the face: An unusual presentation of a common lesion. JAAD Case Rep. 2018;4(4):337-9.

13. Raewyn C, Paul W. Management of congenital lingual dermoid cysts. Int J Pediatr Otorhinolaryngol. 2010;74(6):567-71.

14. Paradis J, Koltai PJ. Pediatric teratoma and dermoid cysts. Otolaryngol Clin North Am. 2015;48(1):121-36.

15. Singh P, Pathania V, Goyal K. Large Post Auricular Epidermal Inclusion Cyst Involving Facial Nerve- A Rare Case Report. Int J Life-Sciences Sci Res. 2018;4(5):2056-8.

16. Sahoo NK, Choudhary AK, Srinivas V, Tomar K. Dermoid cysts of maxillofacial region. Med J Armed Forces India. 2015;71(suppl 2):S389-94.

17. Boffano P, Roccia F, Campisi P, Zavattero E, Gallesio C, Bosco GF. Epidermoid cyst of the temporal region.
Oral Surg Oral Med Oral Pathol Oral Radiol Endod. 2011;112(6):e113-6.

18. Hung EHY, Griffith JF, Ng AWH, Lee RKL, Lau DTY, Leung JCS. Ultrasound of musculoskeletal soft-tissue tumors superficial to the investing fascia. Am J Roentgenol. 2014;202(6): W532-40. DOI: 10.2214/AJR.13.11457

19. Lee HS, Joo K Bin, Song HT, Kim YS, Park DW, Park $\mathrm{CK}$, et al. Relationship between sonographic and pathologic findings in epidermal inclusion cysts. J Clin Ultrasound. 2001;29(7):374-83.

20. Yigit N, Karslioglu Y, Yildizoglu U, Karakoc O. Dermoid Cyst of the Parotid Gland: Report of a Rare Entity with Literature Review. Head Neck Pathol. 2015;9(2):28692.

21. Misch E, Kashiwazaki R, Lovell MA, Herrmann BW. Pediatric sublingual dermoid and epidermoid cysts: a 20 year institutional review. Int J Pediatr Otorhinolaryngol. 2020;138:110265. DOI: 10.1016/j.ijporl.2020.110265.

22. Sakamoto Y, Baba T, Kouzu Y, Koike H, Kasamatsu A, Ogawara $\mathrm{K}$, et al. A case of an epidermoid cyst arising in the maxillary sinus. J Oral Maxillofac Surg Med Pathol. 2014;26(2):228-31.

23. Naujoks C, Handschel J, Braunstein S, Emaetig F, Depprich R, Meyer U, et al. Dermoid cyst of the parotid gland-a case report and brief review of the literature. Int J Oral Maxillofac Surg. 2007;36(9):861-3.

24. Pushker N, Meel R, Kumar A, Kashyap S, Sen S, Bajaj MS. Orbital and periorbital dermoid/epidermoid cyst: a series of 280 cases and a brief review. Can J Ophthalmol. 2020;55(2):167-71.

25. Bolognia J, Schaffer J, Cerroni L. Dermatology. 4a ed. USA: Elsevier; 2017.

26. Zuber TJ. Minimal excision technique for epidermoid (sebaceous) cysts. Am Fam Physician. 2002;65(7):1409-12.

27. Agha RA, Fowler AJ, Rajmohan S, Barai I, Orgill DP, Afifi R, et al. Preferred reporting of case series in surgery; the PROCESS guidelines. Int J Surg. 2016;36:319-23.

28. Agha RA, Fowler AJ, Saeta A, Barai I, Rajmohan S, Orgill DP, et al. The SCARE Statement: Consensus-based surgical case report guidelines. Int J Surg 2016;34:180-6.

29. Klibngern $H$, Pornchaisakuldee C. A large sublingual epidermoid cyst with parapharyngeal space extension: A case report. Int J Surg Case Rep. 2020;72:233-6.

30. Dutta M, Saha J, Biswas G, Chattopadhyay S, Sen I, Sinha R. Epidermoid Cysts in Head and Neck: Our Experiences, with Review of Literature. Indian J Otolaryngol Head Neck Surg. 2013;65(Suppl 1):14-21.

31. Ganesan A, Nandakumar GK. Epidermal cyst of parotid gland: A rarity and a diagnostic dilemma. Case Rep Dent. 2015;2015:856170. DOI: 10.1155/2015/856170.

32. Hegde PN, Kishan Prasad HL, Sunil Kumar Y, Sajitha K, Roy PS, Raju M, et al. A rare case of an epidermoid cyst in the parotid gland - Which was diagnosed by fine needle aspiration cytology. J Clin Diagn Res. 2013;7(3):550-2.

33. Fernandes VLG, De Gouveia Pinto NM, Barreto O, Furtado J, Basuroy S. Epidermoid Cyst of the Auricle: A Common Cyst at a Rare Site. Int J Otorhinolaryngol Head Neck Surg. 2018;07:344-9. 